\title{
On Defining Art Historically
}

\author{
Graham Oppy
}

In "Defining Art Historically" (JAA, 1979, pp.232-250), Jerrold Levinson defends the following definition:

(R) $X$ is a work of art at time $t$ iff $\mathrm{X}$ is an object of which it is true at that some person or persons having the appropriate proprietary right over $\mathrm{X}$, nonpassingly intends (or intended) $\mathrm{X}$ for regard-as-a-work-of-art, i.e. regard in any way (or ways) in which objects in the extension of "art work" prior to $t$ are or were correctly (or standardly) regarded. (p.240)

Moreover, he suggests that this definition can form the generative component of a recursive definition of art, in harness with the initial condition:

(I) Objects of the ur-arts are art works at $\mathrm{t}_{0}$ (and thereafter).

It seems to me that there are numerous difficulties which confront this definition. In particular, there are difficulties involving:

(1) the inclusion of a condition involving "appropriate proprietary rights";

(2) the reliance upon the intentions of independent individuals;

(3) Levinson's account of the notion of "regard-as-a-work-of-art";

(4) the implicit insistence that art is necessarily backward-looking;

Since Levinson's paper has recently received some favourable press (e.g. see Noel Carroll, "Art, Practice, And Narrative", Monist, pp.140-156, at p.155n.9), I think that some discussion of these problems is in order. I shall consider them in turn.

Levinson explains his inclusion of the proprietary-right condition as follows:

What this amounts to is basically ownership -- you can't "artify" what you do not own and thus have no right to dispose of. All your intentions will not avail in such a case, because another person's intention, that of the owner, has priority over yours. (Of course, if he is not opposed to your intention, he can grant you permission to make his possession into a work of art.) (p.237)

I find this view counter-intuitive, not least because it requires that many of our ordinary judgements about the artiness of architecture are -- or at least might be -unfounded. Surely a building which has been owned by none but philistines may nonetheless be a work of art! Moreover, there are questions about some kinds of grafitti ("subway art"), pavement art, etc. And there are also puzzles about how exactly an owner can grant someone else permission to turn a possession into a work of art. 
The proprietary-right condition is hardly an essential part of Levinson's definition; and the simplest way to meet the difficulties which it creates for Levinson's definition is simply to drop it. Henceforth, I shall suppose that the definition has been modified in this way.

One idea which is crucial to Levinson's definition is that a work of art must be a thing which is intended for regard as a work of art. According to Levinson, there are three likely ways in which a connection between current works of art and earlier ones might logically be demanded of an art-aware art-maker, viz:

(a) via the making of something which is externally similar to previous art works;

(b) via the making of something which is intended to afford the same kind of pleasure or experience which has been afforded by previous art works; and

(c) via the making of something which is intended for regard or treatment as previous art works have been regarded or treated.

(Levinson discounts the thought that there are special aesthetic attitudes and/or special artistic purposes as "doomed to failure".) However, there are some fairly obvious problems which Levinson finds for (a) and (b) -- and so he is led to the conclusion that (c) must be correct.

There are two problems which I see for Levinson's position here. First, there is the problem that, in the absence of further constraints, intentions are cheap. Consider any old thing which I've made -- e.g. that mess of broken crockery in the kitchen which resulted from my last temper tantrum, and which has not yet been cleared up. Suppose that I form the intention that -- until I clean up the mess -- I am, and any visitors to my house are, to regard this mess in the way in which works of art have hitherto been regarded. Surely it can't be this easy to make a work of art! (Moreover, surely it is the case that the mess in my kitchen just isn't the sort of thing which can be a work of art.) If there are no further constraints on my intentions, then it seems that, with respect to anything at all, I can form the intention that is to be regarded or treated as previous works of art have been regarded or treated. But I do not think that just anything at all can be a work of art. (Suppose I form the general intention that every single thing is to be regarded or treated as previous works of art have been regarded or treated. Does that make every single thing a work of art?) Moreover, if further constraints are to be supplied, from where could these constraints come, if not from the objects under consideration? But, if we accept this, then we shall have given up the project of providing a historical definition of art.

A second problem for Levinson's suggestion that a work of art must be a thing which is intended for regard as works of art have hitherto been regarded is that it seems quite dubious that such intentions are necessary for the production of art. Levinson (correctly) accuses institutional accounts of art of "coming close to conflating art and self-declared art, art and socially situated art, art and declared art" (p.233); here, however, it seems that the same sort of accusation can be directed at his own view. Indeed, the very examples which he uses to discredit institutional accounts of art seems to undermine his own account as well:

Consider the farmer's wife at a country fair in Nebraska, who sets an assembly of egg shells and white glue down on the corner of a table for folks to look at. Isn't it 
possible she created art? Consider a solitary Indian along the Amazon who steals off from his non-artistic tribe to arrange coloured stones in a clearing, not outwardly investing them with special position in the world. Might not this also be art (and, note, before any future curator decides that it is)? (p.233)

Levinson tries to get around this objection by introducing the notion of an artunconscious intention: intending for regard in some specific way @ characterised in terms of intrinsic features, where @ is in fact a way in which some past art works have been correctly regarded, though this fact is not known to the intender. But this won't do. How could it matter whether the solitary Indian in Levinson's story belongs to an earlier age which predates the rise of art in the world, rather than on a current, geographically isolated primitive culture in which there is no art? Yet Levinson is committed to the view that, in the latter case, the Indian's product is art (because it is the product of an "art-unconscious intentions") but, in the former case, the Indian's product is not art (since it cannot then be the product of an "art-unconscious intention").

On the basis of these arguments, I think that it is reasonable to conclude that position (c) cannot be defended. Furthermore, I would suggest that there is a fourth way in which a connection between current works of art and earlier ones might be demanded of an art-aware art-maker, viz:

(d) via the making of something which is internally similar to previous artworks (where this internal similarity is not to be spelled out in terms of aesthetic attitudes or artistic purposes).

However, I will not here pause to consider whether a proposal which conforms to (d) could be used to save Levinson's definition. (One obvious potential problem is that a proposal which conforms to (d) will surely have the makings of a non-historical definition of art. Hence, the price of finding a satisfactory account of the connection between present and past art may be to give up the project on which Levinson has embarked.)

Another important difficulty for Levinson's definition involves his explication of the notion of regard-as-a-work--of-art. According to Levinson, this notion is to be taken to mean regard in any of the ways works of art existing prior to now have been correctly regarded. In defence of this view, Levinson quite plausibly argues that it is hopeless to try to describe this regard by specifying fixed characteristics -- e.g. "with full attention", "contemplating", "giving special notice to appearance", "with emotional openness", etc. -- because it is impossible to locate a unitary aesthetic attitude or regard common to all of the ways we approach, have approached, and will approach works of art. However, the important question is whether he has provided a satisfactory alternative.

I do not think that he has. The problem is simple: There is no doubt that art has been, and is still, properly regarded as a hedge against inflation -- but it is not true that everything which is properly regarded as a hedge against inflation is art. (This example can be multiplied in obvious ways -- art is also quite properly regarded as "something of great value", "one of the highest pinnacles of human achievement", "an important ingredient in the education of the young", etc.) 
Levinson almost sees the possibility of this sort of objection. He considers a case in which Italian Renaissance portraits come to be used for thermal insulation, and are found to be quite suitable for this task. In order to rule out the conclusion that it would then be the case that anything subsequently intended by its maker to be used for thermal insulation is art, Levinson claims that can appeal to a notion of correct regard for works of art. But it is hard to see how anything short of an appeal to the notion of aesthetic regard -- i.e. to the sort of notion which Levinson explicitly disavows -- can provide an answer in the case of hedges against inflation. Moreover, it is debatable whether Levinson really has an answer in the case of thermal insulation. After all, in the imagined case in which there is an unparalled need for insulation, there would be nothing incorrect in one's regarding Italian Renaissance portraits to be suitable for use as thermal insulation. Of course, one is tempted to say that this would not be to treat the portraits as art. But, equally plainly, this line is not available to Levinson.

In "Refining Art Historically", Levinson attempts to meet this objection. He suggests that what is needed is the notion of "relatively complete ways of regard".

I do not think that this response is adequate. In particular, I do not see that there is any way of understanding the notion of a "relatively complete way of regard" on which Levinson's suggestion is plausible.

On one construal, a "relatively complete way of regard" would be a way of regard which includes enough of the individual ways in which works of art have hitherto been regarded (e.g. "with attention to brilliance of colour", "with attention to tonal contrast", "with attention to nuances of hue", "with attention to the interrelationships of shapes", etc.). Even if we ignore the delicate question of how to determine what is enough, there is an obvious difficulty for this suggestion -- namely, that there are many things which have been given relatively complete ways of regard (in this sense), and yet which are not works of art. Consider clouds, for example. There are numerous aesthetic predicates which are properly applied to clouds -- and so there are numerous individual ways of regard which are proper for clouds. If we collect these individual ways of regard together, we shall have a "relatively complete way of regard". But there can be no purely quantitative test which disqualifies this "way of regard" and yet which does not also disqualify "ways of regard" which are appropriate to works of art.

On a different construal, a "relatively complete way of regard" would be a way of regard which fails to omit certain crucial individual ways in which works of art have hitherto been regarded. This suggestion seems more obviously hopeless than the first -- for, given the recent history of art, it is hard to think that there are any such "crucial individual ways". Given that readymades, found objects, and the "objects" of conceptual art are all genuinely art, it seems very doubtful that there must be "crucial individual ways of regard" to which artists at any given time must attend. (Perhaps it might be suggested that what is needed is the inclusion of "crucial individual ways" which rely directly on the concept of art -- e.g. "with attention to its location in the history of art", "with attention to its status as a work of art", etc. However, this would rule out any art produced with "art-unconscious intentions".)

Finally, it might be suggested that "relatively complete ways of regard" are structured ways of regarding works of art (and not merely mereological sums of individual ways of regarding works of art). That is, it might be said that there are certain constellations of individual ways of regarding works of art which serve as the touchstone for the future production of art. But, again, this suggestion seems to run counter to the revolutionary nature of modern art. Duchamp's "Fountain" was not 
intended for regard in any relatively complete way in which contemporary sculpture had been regarded. (Duchamp did not intend that people should look at his urinal in the way that they looked at a Rodin. Perhaps he may have hoped that some people would be stupid enough to do so -- that would have been an even better joke. But "Fountain" was clearly intended to be "cerebral" in a way that no previous sculpture had been.)

Perhaps there is another way in which the notion of "relatively complete ways of regard" can be construed. However, I do not see that there is any way that Levinson can use it to rescue his theory: for either the notion is given no precise interpretation (in which case the definition of "work of art" may be extensionally correct, but in which case the definition of "work of art" will also be unilluminating); or else the notion is given a precise interpretation (in which case the definition of "work of art" is not even extensionally adequate).

The final difficulty for Levinson's definition which I wish to discuss concerns his insistence that art is necessarily backward-looking. We have already seen that there seem to be intuitively acceptable counter-examples to this claim. However, I now wish to argue that Levinson's definition requires that the concept of art developed in a way which is almost certainly contrary to the facts.

Levinson's view seems to be that there must be parallel development of art and the concept of art. Since an art-aware art-maker is one who forms the intention that certain objects are to be regarded in ways that works of art have hitherto been correctly regarded, it seems that an art-aware art-maker must have the concept of a work of art.

However, there is a widely accepted story which holds that nothing at all like our conception of art and the arts developed until about the seventeenth century. Of course, this conception of art and the arts had antecedents in earlier ideas -- e.g. in the Greek conception of an art. Nonetheless, "art as understood in Western culture" -- i.e. the notion which Levinson claims to be investigating -- did not have a gradual develop in the way that Levinson's theory suggests. (I do not see how Levinson can account for the fact that the painting of the fourteenth century was art at that time even though nothing like our concept of art had yet been developed.)

There may be further difficulties which face Levinson's definition. In particular, I think it could well be disputed that the primary notion to be defined is that of "work of art at time $t$ " rather than simply "work of art". However, I shall close my criticism by describing a case which -- given suitable modifications -- I think provides severe difficulties for any definition of art which seeks to characterise works of art exclusively in terms of relations between those objects and intentions or actions involving other entities (such as "the art world" or "prior works of art").

Consider an artist $X$ who makes several attempts at a painting. Suppose that $X$ is a marvel at execution, but not very good at composition. Each time that he starts out to make the painting, he has a very clear idea of what the final product will look like -- but, each time, after he has performed only a few brush strokes, he realises that the clear idea which he has is a clear idea of a dreadful painting! (By hypothesis, the realisation is independent of the brush strokes which he makes -- it is the 
contemplation of his clear idea which leads to the realisation of the worthlessness of the intended product.) Nonetheless, out of sheer bloody-mindedness, $\mathrm{X}$ forces himself to finish each canvas, as a punishment for his compositional failure -- and then he destroys the canvas in a fit of rage.

Up until the time at which $X$ realises that the idea upon which he is working will lead to a terrible painting, he does intend to produce a work which will be regarded in the ways in which works of art have hitherto correctly been regarded. However, it does not seem to be correct to say that, at that time, he has already created a work of art. (Otherwise, it seems that we would quickly be forced to the absurd conclusion that, at the moment at which a bare canvas is created in a factory, it is already a work of art -- since it is produced with the intention that, at some later time, and after it has undergone certain modifications, it will be regarded in the ways in which works of art have hitherto correctly been regarded.)

However, after the time at which $\mathrm{X}$ realises that his idea is an idea of a terrible painting, there is no sense in which $\mathrm{X}$ has the intention to produce a work which will be regarded in the ways in which works of art have hitherto correctly been regarded -for, thereafter, it is X's intention that no-one shall regard the work in any way at all and, moreover, it is also his intention that he shall soon destroy it. So it seems that -contrary to my intuition -- Levinson's definition must lead to the conclusion that $\mathrm{X}$ is not producing works of art.

One intuition which underlies this case is that definitions of art which seeks to characterise works of art in terms of relations between those objects and intentions and actions involving other entities will have great difficulties in giving a proper account of bad works of art. I do not see that there is any way that Levinson's account can be modified to explain how, in the case described, $\mathrm{X}$ has managed to produce a bad work of art.

Levinson discusses an example due to Sartwell. This example is intended to make the same point as the example I have just given. However, I do not think that this example is convincing.

The difficulty is that the success of this objection depends upon the assumption that a "fake" is not a work of art. I doubt that this assumption should be granted. (Certainly, it should not be granted without some further argument.)

It might be thought that ordinary usage supports the view that "fakes" are not works of art. Surely, if something is a "fake X" then it is not an "X"! Well, certainly, a fake Rembrandt is not a Rembrandt. But a fake Persian carpet is a carpet; it's just not a Persian carpet. Equally, a fake Rembrandt painting is a painting; it's just not a Rembrandt painting. So far, then, we don't have any reason to say that a "fake" is not a work of art. (Note that we don't use the expression "fake work of art". This suggests that, if anything, ordinary usage is on the side of the view which says that "fakes" are works of art.)

Moreover, there are theoretical reasons for holding that "fakes" are works of art. In particular, there is the point that it really would be odd to say that a fake Rembrandt painting is not a painting. Yet surely anything which is a painting is a work of art. (In general, it seems odd to suppose that the ontological status of entities should depend upon the intentions of their creators. A really inept copy of a Rembrandt performed with no intention to deceive, but done rather as a painterly exercise, surely counts as a (bad) work of art. Why, then, should a much better copy performed with intention to deceive, not count as a work of art?)

No doubt this issue needs to be discussed further. However, I think that enough has been said to show that it would be unwise to rely on an objection to 
historical definitions of art which supposes that fakes are not works of art. Other cases can be invoked to make the same point, but without the controversial assumption.

I mentioned earlier that one might think that Levinson's definition can be rescued by framing it solely in terms of connections between present objects and prior works of art (rather than in terms of connections between intentions involving present objects and prior works of art). Moreover, I also noted that a likely problem for this proposal is that it will provide material for a non-historical definition of art (in terms of whatever it is that specifies what kinds of connections which obtain between present objects and prior works of art can serve to bring it about that those present objects are also works of art). I think that now it might be useful to explore this proposal a little more.

There certainly seems to be something correct in the suggestion that art feeds on its past. Much art can quite properly be understood as a modification to, or as a reaction against, earlier art. However, this is not to say that art can be defined in historical terms -- i.e. that the content of the notion work of art can be captured in some sort of recursive definition which recapitulates the history of art.

Moreover, there are a priori reasons for thinking that it is unlikely that the concept work of art can be given a recursive definition of the sort which Levinson proposes. In particular, there is the difficulty that we need to be able to account for the fact that we can make modal and counterfactual judgements which involve the notion of a work of art, e.g. that Duchamp's urinal might not have been a work of art (if, say, he had chosen a different urinal to exhibit). If something is a work of art just in case it occupies the right niche in the actual history of art, then it is hard to see how we can make theoretical sense of what appears to be a perfectly reasonable judgement.

Now, to this, it might be replied that what Levinson has given is merely a definition of the concept work of art in the actual world -- i.e. that Levinson has told us how the actual extension of the concept work of art is determined. But, in that case, it is clear that we have not been given a definition of the concept work of art. Moreover, it is not clear how Levinson's account of the determination of the actual extension of the concept work of art can be extended to a complete account of that concept.

Perhaps it might be said that something is a work of art in a world just in case it occupies the right niche in the history of art in that world. But now we have a problem: for how do we identify "the history of art" in a given world? It seems that we need some non-historical criteria which will tell us that a world has (or does not have) a history of art. Yet, if we have such criteria, it seems that we shall be well on the way to a non-historical definition of art.

In sum: it seems to me that, if the concept work of art can be defined, it is highly unlikely that it can be defined in historical terms. Of course, this conclusion immediately raises a host of new questions; however, I cannot hope to pursue them here. 